Revista Iberoamericana, Vol. LXVII, Núm. 197, Octubre-Diciembre 2001, 639-659

\title{
LA RECONFIGURACIÓN DE POLÍTICAS CULTURALES Y MERCADOS CULTURALES EN LOS NOVENTA Y SIGLO XXI EN AMÉRICA LATINA
}

\author{
POR \\ GEORGE Yúdice \\ New York University
}

\section{REESTRUCTURACIÓN DE LAS INDUSTRIAS CULTURALES}

No hay duda de que en América Latina se seguirá escribiendo poesía y ficción, pintando lienzos y creando instalaciones, componiendo y tocando música erudita y popular, escribiendo y filmando películas, diseñando coreografías y bailando profesionalmente, y así en lo que respecta a las otras artes y medios culturales. Lo que sí está cambiando (y de hecho ya ha cambiado en algunas artes y medios) es la manera como se estructuran y administran estos subsectores de lo que hoy en día se conoce como el sector de artes y cultura. Acaso, el ejemplo más visible de esta reestructuración ha sido la distribución gratuita de música facilitada por las nuevas tecnologías como Nullsoft y Napster, ambas adquiridas, respectivamente, por AOL (US\$ 400 millones) y Bertelsmann (US\$ 100 millones) para “salvar” a la industria discográfica, que factura más de US\$ 40.000 millones por año (Yúdice, "La industria de la música” 115). De menor visibilidad pero aun más profundos han sido los efectos de la reorganización impuesta por la competencia global en los conglomerados de "entretenimiento", sobre todo las cinco majors (AOL-Time Warner, BMG, EMI, Sony, Universal), que vienen integrando horizontalmente diversos subsectores de las artes que antes operaban por separado. Esta integración se ve con claridad en la transformación de la industria de la música. A partir de la década de 1980, las grandes disqueras ya no se conciben como simples productoras y distribuidoras de música sino como conglomerados globales de entretenimiento integrado, incluyen, asimismo a la televisión, el cine, las cadenas de disqueras, las redes de conciertos, el cable y satélite-difusión, y recientemente, Internet. "La industria fonográfica, como a veces se la llama pintorescamente, busca desarrollar personalidades globales que puedan ser comunicadas a través de múltiples medios; grabaciones, videos, películas, televisión, revistas, libros, y mediante la publicidad, el agregado de productos y el patrocinio de bienes de consumo [...]. En este final de siglo, la industria de la música es un componente integral de una red globalizante de industrias interconectadas de leisure (que no es sinónimo de ‘ocio') y entretenimiento” (Negus, Producing Pop 1).

El sector de artes y cultura se está reestructurando en tres conjuntos integrados. Se han constelado, por ejemplo, libros, música, radio, cine, televisión, y prensa, cada uno de los cuales se alimenta recíprocamente y ya empiezan a enlazarse en fusiones multimediáticas 
e interactivas de televisión, computadora e Internet. Otra constelación incluye artesanías, festivales, museos, folclore, artes visuales, y artes escénicas, reunidas en torno al turismo, que a su vez mantiene relación con las industrias de transporte y hotelería y de programas universitarios especializados en el estudio del patrimonio nacional y local. En tercer lugar, podría destacarse una constelación que reúne al diseño industrial y de la moda, la fotografía, revistas especializadas, etc., que se aglutinan alrededor de las artes aplicadas. Cabe observar que estas constelaciones también se entrelazan. Por ejemplo, la informática y la televisión están integrando aspectos de la producción museológica, las cuales culminan en presentaciones al estilo Disneyworld e inclusive en shoppings en los que el arte y el diseño se venden como cualquier otra mercancía, inclusive en Internet (Mirapaul, "Museums Find"). Los blockbusters, que congregan a centenares de miles de visitantes, constituyen los museos en motores de desarrollo urbano de manera semejante a los Disneyworlds y los estadios de deportes (Dobrzynski, "Blockbuster Shows”). Hasta aquí la reestructuración del sector de artes y cultura conforme a criterios económicos y tecnológicos; pero también se está reconfigurando conforme a presiones que surgen del sector mismo de cultura y artes. Como señala García Canclini, la institución del arte también se ha reestructurado transnacionalmente, de manera que el mercado depende de "museos, editoriales y círculos académicos que influyen sobre los criterios estéticos y el prestigio de los artistas, así como de los expertos que los consagran”. (García Canclini, “Opciones de políticas culturales”). Gerardo Mosquera (“Arte y globalización”) ha observado que la "globalización necesita lenguajes, instituciones y usos internacionales que hagan posible la comunicación en escala planetaria”, y es evidente que el mundo de la cultura, sobre todo las exposiciones de arte, proporciona esos lenguajes e instituciones. Añade, además, que la globalización no se limita a "patrones culturales cosmopolitas eurocéntricos”, sino que más allá de los conocidos y celebrados “fenómenos de hibridación, resignificación y sincretismo”, también ha visto la emergencia de “orientaciones e invenciones desde posiciones subalternas”. Esta observación parece contener la presuposición de que la “deseurocentralización” conlleva una capacidad de acción autónoma (en el sentido del concepto angloamericano de agency), constatada en la manera en que los subalternos se apropian o asumen las "penetraciones culturales”, y una nueva configuración "local-periférica” no determinada por o desde los centros.

Mosquera tiene razón al observar que "el auge de las comunicaciones, las migraciones, las conexiones económicas” han producido una "intrincada, conflictiva articulación de fuerzas” céntricas y periféricas, pero me parece que se puede caracterizar esta situación como menos propicia para las periferias y más como el resultado de un capitalismo que necesita deseuropeizarse en la medida que se culturaliza, por tanto requiere de mayor receptividad en contextos totalmente heterogéneos. Creo que el concepto de una "nueva división internacional del trabajo cultural” capta esta necesidad de ajustar los contenidos a las circunstancias locales, sin por ello eliminar la articulación de fuerzas internacionales. Toby Miller propone este concepto para captar los procesos de diseminación y entrelazamiento de la producción de mercancías culturales en varios continentes. Ambos, trabajo intelectual y material, se distribuyen mundialmente en red y muestran lo inadecuado del modelo mercantilista según el cual las materias primas se trasladaban del tercer al primer mundo para la producción de manufacturas. En la era posfordista, la cultura, 
semejante a la producción de ropa o automovilística, se diseña en un país, se procesa en otros, se promociona en varios lugares y se consume globalmente. El país de origen es significante sólo en la medida que genera valor añadido en un contexto en que las diferencias aguzan la demanda; pero no por eso el lucro se mantiene en las localidades sino que corresponde a las empresas transnacionales (Miller, “The Crime of Monsieru Lang”).

Este arreglo se fundamenta por el régimen de propiedad, que conforme a la legislación que acompaña a los tratados comerciales, pasa cada vez más a manos empresariales, las cuales se quedan con el lucro generado por la producción de contenidos. Ésta toma la forma de una maquilación. Hay centros de comando y control de las industrias culturales, y aun cuando se deje de producir en estos centros, las ganancias se acumularán en las empresas que tienen sede allí. Por otra parte, los ingenieros de software, los diseñadores, los cineastas, los artistas, se están convirtiendo en trabajadores contratados para proporcionar servicios y contenidos. La mayoría trabaja sin seguro médico y sin derecho a la jubilación.

No hace falta recurrir a las formas más “avanzadas” de (pos)industrialización cultural para tener una idea clara de esta división de trabajo. Todas las formas culturales han sido reestructuradas según este modelo. Las bienales, por ejemplo, han establecido un circuito en el cual circulan artistas y curadores con tal de que ostenten su marca de diferencia local. En muchos casos, los curadores comisionan a los artistas, casi sempiternamente viajeros, para movilizar la labor de públicos locales que a su vez proporcionan el valor añadido a la obra, y por ende su éxito (Yúdice, "Producing the Cultural Economy”). La función del artista va más allá de la del autor y se asemeja a la de los productores que desempeñan funciones curatoriales, administrativas, educacionales, de marketing y de información y que sirven de intermediarios en la política global. Se transforma el acto creativo de manera semejante a lo que acontece en los conglomerados de entretenimiento donde "el centro de gravedad se desplaza [...] de la autoría a la edición-distribución y [...] el nuevo gran protagonista [es] el empresario organizador de productos en busca de demandas" (Azpillaga et al "Las industrias culturales” 65).

Herscovici ofrece un claro análisis de la transformación del bien patrimonial en bien privado en el transcurso del Estado-Nación moderno al estado neoliberal. Explica que la designación de patrimonio o propiedad privada a ser valorada conforme al mercado no responde a factores naturales sino más bien a decisiones políticas (Herscovici, “Globalización” 55). Podríamos elaborar este factor político como un campo de fuerzas definidas por las condiciones de inserción en la economía mundial, los desarrollos tecnológicos, la especificidad de la industria particular, las demandas de las élites nacionales, las necesidades de los ciudadanos y la particular manera en que estas necesidades se transmutan en la demanda de consumidores. Es importante reconocer que cada una de estas fuerzas es conformada por su relación con las otras, de manera, por ejemplo, que la demanda surgida de los ciudadanos no es en sí un fenómeno natural sino que es "filtrada” por el "tamiz" del campo de fuerzas. De ahí que en una coyuntura particular se conciba la demanda como procedente de las "masas”, en sí un constructo sociopolítico, y en otra coyuntura se conciba la demanda como oriunda de una multiplicidad de segmentos, también constructos sociopolíticos y mercadológicos. En el primer caso, el Estado-Nación participa en la conformación de ese público masivo mediante la inversión 
pública en una infraestructura comunicacional y un sistema distributivo que posibilite la igualdad de acceso (Herscovici, “Globalización” 55); en el segundo, al transformarse la frecuencia radioeléctrica en bienes privados, respondiendo a innovaciones tecnológicas y presiones de mercado que orientan la comunicación a mercados segmentados, los contenidos se ajustan a los consumidores que proporcionan mayor rentabilidad. De ahí que en contraste con la comunicación masiva que asegura igualdad de acceso (al menos en su planteamiento ideal), la TV y otros servicios pagos agudizan la brecha entre los que pueden o no pagar y por el acceso. Por añadidura, la inexistencia de un mecanismo autorregulador en el mercado conduce a la oligopolización de los mercados (Herscovici, “Globalización” 56).

La transformación de los sistemas de comunicación mediante procesos neoliberales (privatización, desregulación, eliminación de los servicios proporcionados por el estado benefactor por razones políticas y económicas) resulta en una recomposición y resignificación de territorios y públicos. La transnacionalización y (neo)liberalización de las industrias culturales impone (1) la necesidad de insertarse a una economía supranacional y (2) reestructuraciones para facilitar esa inserción que responden a "una dialéctica de la uniformización y de la diferenciación” (Herscovici, “Globalización” 58). Por una parte, se uniformizan protocolos jurídicos, tecnologías, y formas administrativas; por otra, la acomodación al mercado transnacional requiere la generación de diferencias locales que posibiliten la rentabilidad de contenidos allende las fronteras territoriales. "[C]ada espacio geográfico precisa diferenciarse y construir su imagen mediática a fin de valorarse con relación al exterior para poder insertarse en esas redes internacionales; la cultura es ampliamente utilizada en la construcción de esta imagen mediática” (Herscovici, “Globalización” 58-59). El hecho de que la valorización de localidades y de sus contenidos se hace a partir de la generación de esas diferencias (orquestadas en un principio por el entorno mercadológico transnacional) obliga que los procesos de formación de identidades culturales obedezcan mandatos performativos. En otras palabras, la diferencias no se pueden pensar fuera del entorno del que derivan su valor; de ahí que se pueda argumentar que las diferencias se constituyen dentro de los procesos de globalización (Lacarrieu, “Construcción de imaginarios” 4-5).

Tomar conciencia de esto complica nuestra comprensión de los programas de reivindicación de lo local, pues nos damos cuenta de que la diferencia es el recurso que permite la valoración, inclusive en iniciativas de sociedad civil que no corresponden directamente a mercado. Los territorios que no puedan o no respondan al imperativo performativo proyectado desde el campo de fuerzas serán excluidos de o marginados en los procesos de producción de valor. Desde luego, me refiero a tendencias de absorción de esos movimientos que, como el de los sem terra en el Brasil o los neozapatistas en Chiapas, procuran participar en la distribución de bienes y servicios, sean éstos del Estado, del mercado o de la sociedad civil. Pero también hay movimientos de resistencia, por ejemplo, las Madres de la Plaza de Mayo o Hijos en el contexto argentino, que procuran rescatar la memoria de lo que el Estado y el mercado han invisibilizado y que la llamada sociedad civil no facilita, pues sigue las políticas de representación vigentes. 


\section{RELACIÓN ENTRE DIFERENCIA CULTURAL E INDUSTRIA CULTURAL}

Hay, pues, que someter al examen crítico la reestructuración cultural que se viene produciendo conforme a criterios sociales y cívicos, siguiendo el ejemplo de las ONGsejemplo que Álvarez ("Latin American Feminisms" 306) ha caracterizado como “ONGización”-y sobre todo UNESCO. Javier Pérez de Cuéllar observa, en su introducción al informe de UNESCO: Nuestra diversidad creativa, que "los derechos económicos y políticos no pueden realizarse separados de los derechos sociales y culturales”. La crítica cultural reconoció hace mucho tiempo que las sociedades erigen guardabarreras culturales para vedarle el disfrute de derechos constitucionales a los que no disponen de alto capital cultural y social. Pero hoy en día también se reconoce que la diferencia cultural (v.gr., de inmigrantes, de minorías raciales o sexuales), que ha sido y continúa siendo el fundamento de la exclusión, es también la plataforma legitimadora de la demanda de inclusión. Como señala Hopenhayn (“El reto”), hoy en día la mayoría de los Estados ha instituido el multiculturalismo (definido como reconocimiento de la diferencia cultural) como fundamento de su proceso democratizador. Este proceso, que encuentra apoyo a escala global en las ONGs internacionales de derechos humanos, acaba dándole una justificación instrumental a la cultura. Hopenhayn, por ejemplo, aboga por la viabilización de la representación de las identidades, pues la democratización reside en el reconocimiento logrado por cada identidad en una formación política. Esta recomendación, conforme al sentido común de las organizaciones internacionales (sobre todo UNESCO), es un correctivo necesario a las políticas de clase, que enfatizan la redistribución económica, a menudo sin darse cuenta del papel que la subordinación identitaria juega en la pobreza. No obstante, es importante observar que a menudo la representación identitaria permanece en el nivel simbólico, provocando, además, una performatividad social conforme a la cual se asumen identidades como medio para acceder a la inclusión institucional. La cultura cobra un valor puramente instrumental en dichos casos.

Hay pocas alternativas a estos criterios instrumentales -el económico y el cívico-en la coyuntura actual, en la que los Estados son obligados a reducir el apoyo público a la cultura, recurriendo o a justificaciones expeditivas (para resolver problemas de desarrollo o de conflicto social) y a alianzas (partnerships) público-privadas, borrando así la diferencia entre una ética universalizante (o la reproducción ideológica consensuada) suscrita por el Estado y la búsqueda del lucro por las empresas. Las transformaciones operadas por la globalización de la economía y de la sociedad civil, los concomitantes desplazamientos demográficos y sus repercusiones en las políticas nacionales y locales, la magnificación y la capitalización de lo simbólico debido a innovaciones tecnológicas en las telecomunicaciones y en la industria del entretenimiento han realzado el valor de la cultura como recurso.

De hecho, los nuevos incentivos a la inversión cultural han conducido a una situación en que el aspecto económico y el cívico se coadyuvan. En gran escala, esta interacción se ve en la alianza entre UNESCO y Disney, que muestra hasta qué extremo una organización que representa los intereses de la sociedad civil ha llegado a relacionarse con una megaempresa cuyo propósito es acumular lucro mediante la diseminación de cultura global. No hay duda de que el neoliberalismo ha penetrado a las organizaciones que deben 
cuidar de los intereses ciudadanos, como argumenta Fawcett ("It's a Small Theme Park"). Pero las alianzas entre organizaciones públicas o sin fines de lucro y el sector empresarial también se ven claramente en la expresión cultural de grupos musicales y activistas como Olodum y Afro Reggae, ambos del Brasil. Olodum viene protagonizando la reafricanización de Salvador da Bahia y el renacimineto de un concepto de sociedad civil desde que, en 1979, se formó como bloco afro (grupo o fraternidad que desfila en el carnaval). El protagonismo cultural (la reafricanización) es inseparable de su protagonismo cívico y económico. Olodum se estableció ONG, "que atua na área da militância do movimento negro brasileiro” (Olodum, “Falando”), para realizar una serie de programas sociales que beneficiarían a la mayoría negra y pobre de su barrio Maciel. Según su sitio de Internet, Olodum realiza acciones de combate a la discriminación racial, estimula la auto-estima y el orgullo de los afro-brasileños, defiende y lucha para asegurar los derechos civiles y humanos de las personas marginalizadas, y colabora en campañas para prevenir el SIDA, el cólera, y el deterioro urbano (Olodum, “Falando”). Estas actividades aprovechan la colaboración con un sinnúmero de ONGs, agencias gubernamentales, fundaciones y empresas.

Su promoción de la autoestima para comunidades negras está respaldada no sólo por este curriculum cívico sino también por el consumismo. Fundaron una fábrica donde se producen los artículos (discos, CDs, camisetas, estampas, sombreros y todo tipo de parafernalia para turistas) que luego se venden en una cadena de boutiques, modeladas sobre la base de la tienda de Spike Lee en New York, y distribuidas en los centros comerciales de la ciudad y hasta en el aeropuerto. La Banda Olodum genera sueldos para sus músicos muy por encima del ingreso promedio de la región y con el excedente, que constituye un $30 \%$, apoya las actividades que Olodum-ONG sin fines lucrativos desempeña a lo largo del año. Esos ingresos provienen de su empresarialismo, de su proclividad a aprovechar el turismo, y en el proceso, explotar su propio patrimonio, su identidad cultural, y sus actuaciones musicales.

En forma análoga, los jóvenes del Grupo Cultural Afro Reggae, que surgió después de una masacre en la favela Vigário Geral en Río de Janeiro para promover la no-violencia mediante la música y la cultura, han logrado profesionalizarse a lo largo de los años hasta el punto de grabar un CD para el conglomerado universal. Sus actividades culturales espectáculos de danza, capoeira, circo y música, su aparición en MTV y otros programas de televisión- proporcionan los ingresos para mantener la ONG que se ocupa de la labor cívica (Yúdice, "Redes”). Sin romantizar la participación de las industrias culturales en el trabajo social de estos grupos, podría decirse que los unos necesitan de los otros. Se ha producido una simbiosis público-privada que es característica de las nuevas iniciativas sociales en el contexto de la retirada del Estado benefactor. A la vez, la noción de alianza o partnership confunde los límites entre lo privado y lo público, pues este modelo, desarrollado en Estados Unidos un siglo atrás, y que actualmente sirve como ejemplo a lo largo de América Latina, ha hecho posible que las empresas y los individuos se ocupen de la res pública, a menudo utilizando fondos obtenidos por descuento fiscal (es decir, fondos públicos) para promover agendas que no han sido consensuadas. Y puesto que los que tienen mayor capacidad económica son los que invierten en este tipo de alianza, se reproducen los intereses de los más pudientes, aun cuando parezca que se promueven las causas de los pobres y grupos minoritarios. 


\section{LA CULTURA COMO RECURSO DE GESTIÓN Y ACUMULACIÓN}

Toda esta actividad ha dado como resultado la naturalización del protagonismo del espectáculo y la performatividad como vehículos del desarrollo económico y de la sociedad civil. En los últimos cinco años, a partir de la reorganización de los ministerios de cultura, se empieza a crear un nuevo sistema de gestión cultural que reduce el papel del Estado a simple mediador de colaboraciones entre el sector empresarial (en el cual las telecomunicaciones, vinculadas a las industrias culturales, tienen papel protagónico) y el cívico. Por ejemplo, el sector empresarial en Brasil ha aprovechado las leyes de mecenazgo e incentivo fiscal legisladas en los años '90, en gran parte siguiendo el modelo estadounidense (Pompeu, “O Arte do Negócio”). Y a partir de Brasil, ese modelo se reproduce a su vez en otros países de la región, como Chile y Argentina ("La Ley de Mecenazgo"). Se dice que estas leyes no reemplazan al Estado; no obstante, logran trasladar la responsabilidad de gestión a las empresas, que no tienen que rendir cuentas a nadie, pues no han sido elegidas para administrar la res publica. Puesto que no hay una cultura filantrópica o de organizaciones sin fines de lucro bien arraigada en América Latina, se corre el peligro de que las empresas promuevan sus propios intereses y subordinen la cultura y el arte al marketing. (Ottmann, “Cultura é Bom Negócio”; Wineland, “Rethinking the Philantrhopic Ogre”).

A pesar de este énfasis en el marketing, no debe descartarse la esperanza de que los incentivos a las empresas y sobre todo a las industrias culturales promuevan proyectos artísticos y de sociedad civil. Es ésta la apuesta de García Canclini en su propuesta para la integración cultural de América Latina. Ésta se llevaría a cabo mediante políticas supranacionales que crearían un espacio audiovisual latinoamericano; mercados comunes para libros, revistas, cine, televisión, video y radio; una Fundación para la Producción y Distribución de Medios Latinoamericanos; medidas para regular la inversión extranjera; iniciativas para fortalecer las economías culturales latinoamericanas; una ciudadanía supranacional democratizadora que reconozca identidades culturales locales (García Canclini. Consumidores y ciudadanos 113-14). ${ }^{1}$

Por añadidura, como señala Octavio Getino, la globalización en las industrias culturales “incentiva más que restringe la necesidad de fortalecer o revitalizar las identidades de cada comunidad [...]. Todo hace prever que las reinvidicaciones culturales locales y regionales, crecerán antes que reducirse” ("Las industrias” 60-61). Estas reivindicaciones pueden manifestarse como sangrientos conflictos étnicos, pero el ejemplo de Olodum y Afro Reggae muestra que si se les abre la posibilidad de remuneración, hecha posible por mecanismos de gestión cultural, la manifestación de las diferencias no tiene por qué tornarse violenta, y por el contrario puede tener efectos beneficiosos multiplicadores.

\footnotetext{
${ }^{1}$ Si bien en la primera edición de Consumidores y ciudadanos García Canclini parece poner demasiada confianza en el ejemplo de la integración cultural en la Unión Europea, en la introducción a la edición estadounidense reconoce que aún dentro del contexto europeo se está dando un fuerte proceso de privatización y conglomerización que desatiende valores artísticos y ciudadanos. No obstante, insiste en la necesidad de pensar estos valores en relación con las industrias culturales, pues es mediante ellas que la gran mayoría de la población participa (como televidentes, escuchas, lectores e inclusive productores) en los procesos culturales (“Author’s Preface” 9).
} 
Además de estos posibles beneficios sociales, la cultura -tanto en sus formas tradicionales como en las nuevas manifestaciones electrónicas- contribuye substancialmente a la base económica de muchos países, sobre todo en las ciudades. En Gran Bretaña, por ejemplo, los empleos dedicados a la convergencia entre tecnología y creatividad -diseño, cine, tecnología informática e innovación intelectual/culturalsuperan el $16 \%$ de la población que se dedica a manufacturas y crece a una tasa de $5 \%$ por año mientras éstas disminuyen(Greenhalgh, "From Arts Policy” 85). El caso estadounidense es todavía más impresionante. A pesar de que todavía no se han creado (y acaso nunca se logre crear) instrumentos exactos para medir el sector cultural, los economistas que se especializan en este campo estiman que las artes, el entretenimiento y las comunicaciones alcanzaron US\$ 180 mil millones en 1995 ó 2,5 \% del PIB. Al incluir las industrias del copyright, esta cifra sube a US\$360 mil millones ó 5\% del PIB (Arthurs \& Hodsoll, “The Importance” 104). Desde luego, no todo el lucro generado por esta definición amplia e industrializada de la cultura comporta el compromiso social de Olodum y AfroReggae. El boletín financiero World Watch informa que para 1996 los muñecos fabricados para acompañar películas como la Guerra de las Galaxias, Superman y las películas animadas generaron US\$70.000 millones, mientras que la totalidad de inversiones en los países en vías de desarrollo sólo alcanzó US\$ 46.000 millones, un máximo histórico.

Este último ejemplo nos lleva a considerar otras formas en que la industria cultural genera ganancias y empleos. Si se piensa que el sector artístico opera como el "R\&D” (la investigación y el desarrollo) para el ambiente construido (the built environment) (Chartrand, “The Arts as R\&D”), se hace evidente que este sector no sólo genera trabajos artísticos sino industriales, por lo general exportados a las maquiladoras de los países menos desarrollados. Aun así, la contribución económica de este sector en EE.UU. alcanza, según Chartrand, entre el 6 y el 8,5 \% del PIB. Estas cifras se basan en una definición mucho más amplia de lo que se entiende tradicionalmente por artes y cultura:

\begin{abstract}
La industria de las artes, o más propiamente dicho, el "sector artístico", incluye todas las empresas e instituciones lucrativas, no lucrativas y públicas, inclusive las actividades incorporadas y no incorporadas y las de los artistas auto-empleados, que (a) usan una o más de las artes como factor principal de su producción-v.gr., publicidad, moda, diseño industrial; (b) usan una o más de las artes como mercancías-vinculadas con el consumo, v.gr., aparatos para entretenimiento a domicilio, revistas, diarios; y/o (c) producen una o más de las artes como su producto final, es decir, crean, producen, distribuyen, y/o conservan bienes y servicios en las artes literarias, mediáticas, escénicas, visuales y/o patrimoniales. (Chartrand “Art” 110)
\end{abstract}

Mediante esta definición, Chartrand procura dar luz sobre la enorme contribución de la estética a la producción para así lograr que los administradores de la cultura fortalezcan ese sector y lo reconozcan como generador de empleos. Chartrand es, además, uno de los pocos que al escribir sobre este sector tiene en cuenta los sindicatos, que "constituyen uno de los sectores mejor organizados, educados y poderosos del movimiento laboral en Estados Unidos” (Chartrand “Art” 111).

En América Latina, el sector cultural también es significativo. Como señala Octavio Getino, el sector cultural superó los US\$10.000 millones anuales o el equivalente al 5\% 
del PBI argentino, en el período de 1980 a 1992 (“Las industrias” 54). Pero si se examina con cuidado hacia dónde migran las ganancias de ese sector, nos damos cuenta de que en gran parte son las empresas transnacionales que controlan los derechos de propiedad y la distribución y por lo tanto, las ganancias. Si bien en varios de los países de la región la mayor parte de la programación es producida localmente debido a cuotas de contenido, en la mayoría de estos países el cine estadounidense alcanza entre el $85 \%$ y el $90 \%$ de facturación correspondiente a exhibición en salas y emisión en TV de señal abierta. Por añadidura, las distribuidoras estadounidenses surten un porcentaje casi idéntico en lo que respecta a la distribución. En los otros rubros de las industrias culturales se produce esta misma asimetría.

En la industria disquera, aun cuando la mayoría de la música consumida localmente sea nacional o latinoamericana, las empresas transnacionales controlan más o menos el $80 \%$ de las facturaciones. De todos los mercados mundiales, América Latina ha tenido los de más acelerado crecimiento en los años ' 90 . Si bien sólo es el cuarto mercado del mundo, con una fracción de 6, 2\%, en 1996 logró crecer 20\% en volumen de unidades vendidas y $25 \%$ en valor. El crecimiento se sostuvo en 1997, con un valor de $\$ 2.600$ millones en ventas, representando un crecimiento de $11 \%$, el más alto de todos los mercados, por tercera vez seguida. Las disqueras transnacionales, o majors, consideran a América Latina el mercado que más altas tasas de crecimiento ofrece desde la segunda mitad de la década de los '90. Casi todos los análisis pronostican un crecimiento igualmente acelerado hasta bien entrado este siglo xxı. Considérese, por ejemplo, que el mercado brasileño creció de US\$262 millones en 1992 a casi US\$1.400 millones en 1996 (“Boogie Woogie”).

Tampoco debe creerse que esta nueva coyuntura mantiene la línea divisoria entre arte culto y cultura popular. Los nuevos regímenes de acumulación, asistidos y conformados por las nuevas tecnologías de producción y reproducción electrónica, hacen posible la integración de los dos criterios -el económico y el cívico- que vengo comentando. Por añadidura, estos regímenes de acumulación han favorecido la administración de la cultura a partir de instancias extranjeras, o transnacionales si se quiere, lo cual augura menor competitividad para empresas e iniciativas latinoamericanas. Éste es el gran problema para todas las manifestaciones culturales en América Latina hoy en día. Hay una penetración aún más aguda que en años pasados, pues el $80 \%$ de las industrias culturales son administradas y en la mayoría de los casos también son propiedad de los conglomerados transnacionales.

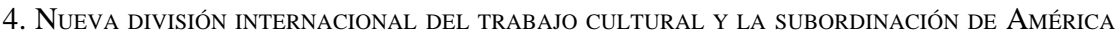
LATINA

Este diagnóstico no implica que las empresas latinoamericanas sucumban ante el auge de la fusión y de la transnacionalización. Más bien las grandes empresas, que ya reunían editoreo, audiovisual y telecomunicaciones -v.gr., las brasileñas Organizações Globo y Abril, el argentino Grupo Clarín- atendiéndose a la misma evolución de TimeWarner o Bertelsmann -o las que se fusionaron a partir del audiovisual-v.gr., la mexicana Televisa y el venezolano Grupo Cisneros (dueños de Venevisión), hoy en día son parte del mismo sistema transnacional de fusiones y adquisiciones que caracteriza a la nueva 
división internacional del trabajo cultural, y que a su vez responde a la necesidad de reducir los costos de operación (sobre todo eliminando puestos de trabajo excedentes y abaratando la mano de obra), así como de aumentar los rendimientos por medio de una base de usuarios más consolidada. Las empresas latinoamericanas arriba mencionadas son nudos importantes en la diseminación de riesgos y de propiedad a través de redes de localidades metropolitanas tanto en el mundo industrializado como en el que está (sempiternamente) en "vías de desarrollo”. El Grupo Cisneros, por ejemplo, forma parte de varias redes empresariales: la cadena satelital Galaxy Latin America, que también incluye a la empresa mexicana Multivisión y el conglomerado brasileño Abril; la empresa de televisión paga Ibero-American Media Partners, que reúne a Hicks Muse Tate \& Furst (EE.UU.), El Sitio (Argentina, pero además con operaciones en Brasil, Estados Unidos, Chile, Colombia, México y Uruguay), Chilevision, Radio Chile, Caribbean Communications Network (Trinidad); AOL.com y centenares más. Igualmente, el Grupo Televisa forma el núcleo latinoamericano de Sky -otra alianza entre telecomunicaciones y entretenimiento- con la News Corporation de Rupert Murdoch (Reino Unido), Organizações Globo (Brasil) y TCI International (EE.UU.) (Yúdice, "La industria” 144).

Esta nueva división corresponde a un nuevo régimen de acumulación según el cual se poseen los derechos y se gerencia la producción de contenidos a partir de centros de comando y control diseminados en red (Castells, The Rise), y la creación cultural es tratada cada vez más como un servicio contratado (Rifkin, The Age of Access). De ahí que la producción cultural local no contribuya a mejorar la posición económica de los países en vías de desarrollo. Al contrario, la brecha económica se ensancha cada vez más. Agrava esta situación el hecho de que las empresas transnacionales no inviertan en centros de investigacion y desarrollo locales y que se lleven los cerebros más dotados a sus propios centros de comando y control. El resultado es una maquilación de la producción cultural: se controla el proceso de producción desde fuera, y de este modo se abarata el trabajo cultural en las localidades. Esto se evidencia en los nuevos medios, sobre todo Internet, donde la capacidad de contratar la creación de contenidos a escala global ha crecido de forma vertiginosa.

En la medida en que la cultura deviene recurso de acumulación (en el audiovisual, el turismo, el desarrollo urbano, Internet, etc.) y se multiplican las posibilidades de crear contenidos localmente, tanto más aumentan los ingresos de las empresas transnacionales, pues los regímenes de comercio internacional favorecen a los que poseen los derechos de propiedad intelectual. Según Enríquez (“Technology and the Future”), en el nuevo régimen, la acumulación depende de la innovación científica y tecnológica, sobre todo en un orden económico en el que las manufacturas han perdido valor. Por ejemplo, considérese al respecto el caso de la economía latinoamericana más grande, la brasileña, la cual sólo registró 56 patentes en la Oficina de Patentes de los EE.UU. en 1996, mientras que Corea del Sur y EE.UU. registraron 1.500 y 56.000 patentes, respectivamente. Un solo subsector de la industria de propiedad intelectual, la investigación genómica, supera el PBI de la Argentina. Por añadidura, los cortes de presupuesto y las privatizaciones que imponen las instituciones financieras internacionales y que la mayoría de los estados latinoamericanos aceptan en su acomodación al neoliberalismo, han debilitado las universidades, lugar idóneo para la generación de propiedad intelectual. En Argentina, por 
ejemplo, el debilitamiento avanza con la Ley de Educación Superior aprobada por el menemismo en 1995, y hace poco se agudizó aun más con la instalación del arancelamiento y la restricción del ingreso (Tatti, “Delich propone”). Bajo estas circunstancias, la brecha entre países posindustriales y los que no logran generar propiedad intelectual (por más que se industrialicen o "maquilicen”) no puede sino crecer en esta era de la nueva economía ("Se amplía la brecha”).

Este régimen de acumulación se extiende al campo cultural, en el cual las empresas transnacionales poseen los derechos tanto de la mayoría de los contenidos producidos hoy en día como de los repertorios musicales y audiovisuales, resultado de la compra de derechos o de las fusiones y adquisiciones (Oliva, “Cerrando la brecha”). Se ha argumentado que es sobre todo en el campo cultural donde se "cierra la brecha” entre los países del norte y los latinoamericanos, pero se trata de cerrarla en el consumo y no en la producción: "Somos subdesarrollados en la producción endógena para los medios electrónicos, pero no en el consumo" (García Canclini, Consumidores y ciudadanos 26). Esta "actualización” en el consumo es justamente lo que las industrias culturales buscan; se trata de captar la atención de los espectadores y usuarios mediante el entretenimiento para vendérselo a los sponsors (Piscitelli, La generación Nasdaq). Ya la publicidad en televisión había logrado convertir esa atención en lucro, pero la expropiación del valor del trabajo que hacemos al atender e interactuar en Internet es todavía más explotable. Explica Tiziana Terranova que la "nueva economía” de las punto-com se sustenta mediante una doble explotación: de los artistas, diseñadores, programadores, etc. que laboran 12 horas por día o más a cambio de acciones (stock options), cuyo valor se desploma cuando los accionistas se cansan de invertir en empresas que no rinden retorno, y de los usuarios, que co-laboran manteniendo chats y otras actividades que los portales solicitan bajo la apariencia de una "oferta" gratuita cuando en realidad son los usuarios que la "regalan” (“Free Labor” 36).

La sinergía de Internet y entretenimiento añade al repertorio de explotaciones la expropiación del valor que reside en lo inmaterial, en nuestros deseos e impulsos estéticos. Por añadidura, se argumenta que el consumo cultural e informacional no conduce al conocimiento, para el cual se necesita del "filtro" de uno o varios marcos interpretativos, que ya no son operativos en Internet e inclusive en la reorganización de la cultura por el entretenimiento ciberindustrializado. Hasta el sector universitario se ve afectado por este nuevo régimen, sobre todo en ciudades dedicadas a la generación de propiedad cultural orientada al entretenimiento, como Miami, donde la educación artística sirve para crear nuevos sujetos económicos de gran capacidad innovadora, pues se opera según la premisa de que la innovación inmaterial es el nuevo combustible de la economía global (Rifkin, The Age of Access; Yúdice, "Globalization and”).

\section{LA INDUSTRIA EDITORIAL}

En lo que respecta al campo de la literatura, que según Rama (Rubén Darío 124-25) fue el único sector -vis-à-vis la economía, la ciencia, la política, etc.- en que América Latina estaba a la par de la modernidad europea y norteamericana, los derechos han pasado a conglomerados transnacionales mediante las adquisiciones. A través de este proceso de adquisición, las empresas españolas han recuperado su antiguo dominio en el sector 
editorial, reflejo además de la competencia global en la que los conglomerados financieros y de telecomunicaciones españoles están desplazando a Estados Unidos como primer inversor en muchos países latinoamericanos, sobre todo Argentina, Brasil, Chile y México (Bonet y de Gregorio, “La industria cultural española”). Los informes económicos hacen hincapié en las inversiones en finanzas, utilidades y telecomunicaciones, este último sector sirve como matriz para la aglutinación de las industrias culturales en sus nuevos formatos, sobre todo relacionados a Internet. A este respecto, Telefónica, el mayor y más exitoso inversor extranjero en América Latina (Rehak, "Spain”), también dueño del tercer proveedor global de Internet en el mundo -Lycos Terra, con US\$3.000 millones de reservas- está mejor posicionado que cualquier otro en la región, a pesar de las pérdidas que aquejan a este sector (Zafra y Muñoz, “Telefónica impulsa”). En estos momentos, la fusión de Terra y Telefónica Media, siguiendo el modelo de la fusión AOL y Time Warner, hace patente el carácter transnacional y fusionado de estas empresas. Con esta fusión pasarían a la nueva empresa, Terra Media, Endemol (la productora de Gran Hermano); Telefónica Sport (que posee parte importante de los derechos de explotación de los partidos de la Liga Española de Fútbol); la productora cinematográfica Lola Films; y la disquera venezolana Rodven (originalmente del Grupo Cisneros y ahora 51\% de Telefónica) (Redacción Punto-com, “Según El País”).

En la industria editorial los procesos aquí descritos llegan a proporciones alarmantes. Se ha argumentado que si bien los procesos de globalización diseminan ampliamente los productos de los países dominantes e inclusive productos de países periféricos dentro de la lógica e intereses de los primeros (v.gr., la World Music), esos mismos procesos aminoran la diversidad cultural a escala mundial, a menudo previniendo que las industrias culturales locales no fusionadas -como por ejemplo las editoriales independientes o las productoras indies (por contraste con las majors) de cine y música-apenas sobrevivan con mercados reducidos e inclusive sucumban debido a las condiciones arduas de distribución. Los grandes conglomerados editoriales (Time Warner, de Estados Unidos; Vivendi [antes Havas, que ya había absorbido a Hachette], de Francia; Bertelsmann, de Alemania; Planeta y Santillana, de España) han restringido la diversidad del libro mediante la búsqueda del bestseller, que conduce a producir una "menor cantidad de títulos con grandes tiradas y fuertes ventas, en un proceso de selección basado exclusivamente en criterios comerciales" (Harari, "La edición independiente” 7). Por añadidura, el control de los sistemas de distribución, que asegura el éxito competitivo según estos criterios comerciales -v.gr., en Francia las cadenas, megalibrerías y los supermercados venden más de la mitad de toda la oferta editorial (Rapport d'activité 1998) - reduce la entrada al mercado de "literatura en general y ciencias humanas" (Harari, "La edición independiente” 4).

Este control de la industria editorial se ha agravado, a pesar del mejoramiento de las economías latinoamericanas en la década de los '90, debido a una agresiva política de adquisición por parte de las empresas españolas. Estas adquisiciones se dan dentro del protagonismo económico más general de España en América Latina. Por ejemplo, las exportaciones a América Latina se doblaron entre 1990 y 1995 y las inversiones aumentaron más de 1.300\% entre 1993 y 1997, sobre todo en la adquisición de empresas latinoamericanas. El proceso de adquisición y la inversión directa en empresas locales fueron facilitados por políticas de privatización promovidos por los gobiernos 
latinoamericanos, y al mismo tiempo presionados por instituciones financieras internacionales como el Fondo Monetario Internacional (FMI) y el Banco Mundial (BM). En el sector cultural, la privatización afectó sobre todo a los canales de televisión.

En lo que respecta al sector editorial, asombra la cantidad de adquisiciones, especialmente de los sellos más reconocidos. Entre las adquisiciones españolas, se pueden enumerar: la mexicana Joaquín Mortiz y la argentina Emecé, adquiridas por Planeta; la argentina Sudamericana por Plaza y Janés, subsidiaria de Bertelsmann; la argentina Javier Vergara, por Ediciones B, subsidiaria del Grupo Zeta; la argentina Aique y las brasileñas Atica y Scipione por Anaya, subsidiaria del Grupo Havas de Francia. El resultado es que las empresas europeas controlan los mercados editoriales latinoamericanos más importantes. El Grupo Santillana tiene dieciocho subsidiarias, la más visible de las cuales es Alfaguara. Lumen, Debate, Océano están en casi todos los países de la región. Grijalbo, sello de la italiana Mondadori -propiedad del derechista Berlusconi, que recién firmó convenio con Bertelsmann- opera en Argentina, Chile, Colombia, México y Venezuela. El gobierno español fomentó y estimuló este dinamismo de adquisiciones y ocupación de mercados latinoamericanos, como se verifica en el plan de la Dirección General del Libro de España, según el cual se buscó la "expansión y consolidación en Iberoamérica de las pequeñas y medianas [editoriales españolas]” (Rodríguez Lafuente, “Discurso”). Y si esto no fuera bastante, Bertelsmann procura adquirir a las pocas editoriales independientes de importancia, como Paidós y De la Flor, ambas argentinas (Sánchez, "Los nuevos dueños”).

Añádase a todos estos datos el que las cadenas de librerías -Barnes \& Noble, Borders, Crisol, Fnac, Virgin- también están promoviendo bestsellers y libros que no tienen que ver con literatura y ciencias humanas, y además que Internet está transformando tanto la distribución como el formato mismo de la lectura, todos estos factores permiten vislumbrar catastróficas dimensiones de la crisis del libro en todo el mundo. Por una parte, la búsqueda del bestseller y la concentración de la distribución en los conglomerados que sólo buscan el lucro tienen el resultado de aminorar el papel del editor como filtro de valores, como intermediario cultural. "El editor [...] abandona cada vez más su rol de filtro; la selectividad, que crea la imagen propia de cada editorial y que es un aporte cultural significativo" (Harari, “La edición independiente” 7). Por añadidura, tanto el proceso de las majors como la adquisición por Bertelsmann del 50\% de las acciones de Napster, indica que el régimen del copyright prevalecerá por encima de otras consideraciones, inclusive los derechos de autor. Por añadidura, la misma Bertlesmann se alió con AOLTime Warner, EMI y Real Networks en la creación de otra distribuidora de música en Internet, MusicNet, que junto con Duet (creada por Sony y Universal) asegurará que los 72 millones de usuarios que había atraído Napster paguen por la música que bajen. Todos estos movimientos auguran que los conglomerados tendrán aún más control de la distribución, puesto que se espera que Internet vaya aumentando el volumen de todo tipo de “contenidos” (inclusive imágenes y textos) adquiribles en forma digital. El auge de la distribución, licenciada por estas vías, asegura que las tentativas de autodistribución por el rey de los bestsellers Stephen King o por una estrella de la música como David Bowie sean menos factibles. En todo caso, estas tentativas no han hecho sino preparar el camino para que Internet sea una vía de distribución factible (Dubner, “What Is”). 
No hay duda de que las grandes editoriales lucharán en todos los foros posibles, desde las cámaras locales hasta la Organización Mundial de Comercio, para que el copyright y los derechos de propiedad intelectual se mantengan bajo el control empresarial. De hecho, las condiciones bajo las cuales se produce “contenido" para los nuevos medios reducen a los creadores (escritores y artistas) a proveedores de contenidos, recurso sumamente explotable en la "nueva economía”. Los portales de Internet requieren "cerebros de obra”, y cada vez más estructuran las condiciones del trabajo intelectual y cultural como un servicio contratado. Es justamente por esta razón que la provisión de “contenido” para las empresas transnacionales y fusionadas no contribuye a las economías locales. La nueva división internacional del trabajo cultural -que podríamos denominar "maquilación” de la cultura-asegura que los derechos de propiedad y el lucro, que les facilitan la legislación fraguada en los acuerdos comerciales (OMC, OECD, NAFTA, MERCOSUR), se mantengan en manos de los conglomerados.

\section{REPERCUSIONES EN LA LITERATURA}

No es evidente todavía cómo repercutirá este régimen de producción cultural en la literatura convencional, que en todo caso siempre se ha creado a partir de la intertextualidad. Irónicamente, ese modus operandi puede ser interrumpido por la extensión de validez del copyright y por la "navegación” característica de Internet, cuyo uso hasta la fecha se ha basado en las leyes de fair use. Un efecto del control de distribución de libros y de creación de contenidos por las majors es que promueven una lectura convencional, tanto de $e$-libros como de páginas web. Como señala la webartista brasileña Giselle Beiguelman, esas empresas simplemente mimetizan la forma del libro impreso, reeditándolo sobre un nuevo soporte, manteniendo, no obstante "criterios biblioteconómicos de organización de contenido” (Beiguelman, O libro depois do livro).

Ante este cuadro un tanto desesperante, ¿qué puede ser/hacer la literatura? Me limitaré a mencionar dos opciones que se enfrentan a la absorción omnívora del trabajo intelectual dentro del nuevo régimen de acumulación. Por una parte, siguiendo a Nelly Richard, se puede intentar paralizar la maquinaria de producción de sentido, que es justamente el medio más eficaz del capitalismo neoliberal, sobre todo en situaciones como las del cono sur donde esa producción de sentido borra la memoria de sus propias condiciones de posibilidad. Es decir, las industrias de producción de sentido -desde el libro de entretenimiento, la televisión, la universidad orientada al funcionalismo de las ciencias sociales, y los portales de Internet-procuran superar las contradicciones sociales y políticas mediante la acomodación al consumo en su forma transnacionalizada. Para Richard, aun el énfasis en las políticas contestatarias de identidad diseminadas desde la “academia metropolitana” (siguiendo teorías poscoloniales, posmodernas, subalternistas y de estudios culturales) acomodan las energías contestarias a dispositivos de sentido (representatividad) que al fin de cuentas facilitan su absorción por el Estado mediador entre el capital transnacional y los ciudadanos (Richard, “Globalización académica”). De ahí su opción por expresiones teóricas (Thayer) y estéticas (Eltit, Olea) que rehúsan la institucionalización, vehículo de su funcionalidad. Acomodar las diferencias sociales en los aparatos de representación, es, pues, integrar resistencias al régimen de sentido y 
acumulación neoliberal suscrito por la concertación chilena. Es justamente por esta razón que Richard critica las tendencias editoriales y artísticas vigentes:

\begin{abstract}
Vista desde la literatura, la situación de hoy parecería señalar que el reciente apoyo editorial a las tendencias estimuladas por el mercado literario privilegia a las "concepciones de la literatura destinadas a un público masivo que busca mayoritariamente una comprensión del mundo narrado en un lenguaje representacional y realista, más o menos adecuado con lo establecido" (Olea, "Brevísima relación” 142), desatendiendo aquellas otras escrituras que operan un descentramiento de la convención literaria o que llevan el significante a transitar por las orillas menos frecuentadas del imaginario narrativo" (Richard, La insubordinación 96).
\end{abstract}

La postura de Richard, en la coyuntura particular en que escribió La insubordinación de los signos (1994), descansa en una suerte de asalto semiótico-anarquista a la maquinaria de la producción de sentido. Pero acaso no sea acertada esta estrategia -embargar la "conformidad discursiva"- en el contexto actual. Por una parte, el tipo de escritura a que se refiere Richard se limita a pequeñas capas de clase media, soslayando al "público masivo". Por otra parte, esta escritura desconoce las operaciones de la nueva comunicación interactiva, sobre todo a partir de la convergencia de las industrias culturales en Internet, y por tanto, no está en condiciones para descarrilar o afectar esa maquinaria. Básicamente se aboga por estrategias estéticas inherentes a la modernidad para ejercerse en nuevo espacio en el que muchas prácticas de resistencia o embate tienen otro sentido en el nuevo entorno tecnológico político, si bien precariamente aliado a la episteme neoliberalposmoderna.

Así, pues, lo que se supone una ruptura del sentido y de la estética representacional en el contexto moderno, no es sino el protocolo normativo en la era digital. Según declara Chartier en una entrevista, "el texto electrónico no permite [la] percepción [estética] fácilmente, y su tendencia es a la fragmentación o a la ausencia de percepción de la totalidad de la obra” (D’Onofrio, “Las nuevas tecnologías”). Con la digitalización de textos, hay una pérdida del contexto que contribuye a la interpretación, v.gr., todo el material (otros escritos, imágenes, diagramación, etc.) que circunda al artículo en un periódico o revista. Pero la falta en Internet de control editorial o académico más que una pérdida, puede verse como una oportunidad para formular una ética crítica frente al contenido. El mismo Chartier opina que "[h] ay que aprender a plantearse de dónde vienen los textos, qué fuentes tienen, quién los escribió, qué hay detrás de lo que estoy leyendo”, es decir, desarrollar la crítica que Sarlo ya había declarado nula en lo que respecta a la nueva cultura electrónica, pues no infunde, según ella, el distanciamiento requerido para ejercer esa capacidad crítica, particularmente cuando las técnicas y prácticas de uso se subordinan a la lógica del mercado consumista (Sarlo, “Modernidad y después”; Yúdice, “Estudios culturales”). Pero en lugar de lamentar nostálgicamente esta falta, acaso sea más productivo inventar nuevas prácticas críticas. Otra vez Chartier:

[En Francia] se enseña a usar la nueva metodología a todos los alumnos. Partimos de la base de que todo el mundo tiene que conocer esta tecnología del siglo xxi. Además, se trasmiten instrumentos que permiten a cada uno ejercer esta postura crítica, mostrar que 
cada discurso se ubica dentro de determinadas condiciones que responden a proyectos, intereses, perspectivas, que se deben descifrar a través de un proceso crítico. El pensamiento crítico es la principal herramienta frente a los que se lamentan ante la nueva tecnología. Nadie puede pensar en volver al pasado, a un mundo sin pantallas, sin TV. No, el mundo de hoy es así, la técnica existe y va a desarrollarse hacia nuevos usos (D’Onofrio, “Las nuevas tecnologías”).

En respuesta a la recomendación de Chartier de examinar críticamente las condiciones de posibilidad de los medios en que invertimos nuestra atención, y también en parte a las posibilidades estéticas de Internet, la escritoria brasileña Giselle Beiguelman ha creado, entre otros, O livro depois do livro, un ensayo sobre literatura, lectura y mediación en el contexto de Internet (O livro). Lo que interesa a Beiguelman son las "zonas de fricção entre as culturas impressas e digitais [...] as operações combinatórias capazes de engendrar uma outra constelação epistemológica e um outro universo de leitura” (Beiguelman, "Relatório_final.doc”). Y ese universo de lectura reside justamente en la capacidad de crear en o a partir de las intersecciones entre los lenguajes. Internet parece permitir liberar hacia una “obra aberta infinita”, más allá de sus soportes limitantes, que, no obstante, han conformado la lectura y el conocimiento que deriva de ella. "O que está em jogo é a necessidade de engendrar repertórios capazes de transcender as formas (e os conceitos) de livros e páginas como invólucros de idéias”. Para este propósito, O livro depois do livro procura liberarnos de las imposiciones de los browsers (Internet Explorer, Netscape), que mediante el click transforman la masa de imágenes y textos en un proceso de lectura lineal. El resultado es “[u]ma literatura fundada num grau de ironia tão radical que seja capaz de corromper os pressupostos de ordenamento e representação da cultura impressa, forçando não a descartabilidade do livro de papel, mas sim a redefinição do que se espera do livro eletrônico" (Beiguelman, "Relatório_final.doc").

Las nuevas propuestas estéticas en Internet se crean colectivamente a partir de afinidades, y suelen ser interactivas, multisituadas y manejadas en los miles de millones de sitios que, bajtinianamente, conforman el ciberespacio. Algunas composiciones son comparables al lance de dados de Mallarmé, pues se van construyendo "a partir de un conjunto de piezas dadas y de perspectivas narrativas construidas con interfaces computadorizadas” (Beiguelman). Gran parte de esta e-escritura/arte sólo se da en tránsito, por tanto desafiando el tipo de “contenido” ofrecido por las majors. Por añadidura, el hecho de que se esfume la categoría de autor, también quiere decir que no existe el plagio, lo cual crea problemas jurídicos ya que las majors han conseguido imponer su régimen de propiedad. Hay cierta realidad en la caracterización del artista como outlaw. Pues no hay, como ya lo había notado Bajtín, un lenguaje “propio”, ya que el hic et nunc en el que constituye la subjetividad es constituido por el tránsito y cruce de voces (Bakhtin, “The Problem” 89) con diversa inflexión, temporalidad, y ubicación o por el “dislocamiento de archivos en la red” (Beiguelman, “Relatório_final.doc”). La liberación de la lectura propuesta por Beiguelman, ya inherente en la literatura y hecha más factible en Internet, milita contra la apropiación del trabajo intelectual en forma de propiedad. Se produce otra globalización en este proceso crítico, encarnado ya en las manifestaciones contra la globalización de las transnacionales y de los acuerdos comerciales en Seattle, Davos, Praga, Washington, Porto Alegre y Quebec. 
Ya antes del uso masivo de Internet, Deleuze y Guattari habían caracterizado estos procesos de tránsito y cruce como rizomas, o como proceso de navegación, que en Internet consiste en aprehender y surfar links. El rizoma es un "sistema no significante a-centrado, no jerárquico, sin General y sin una memoria organizadora o una automatización central; se define exclusivamente por la circulación de estados” (Deleuze y Guattari, A Thousand Plateaus 21). De hecho, uno de los sitios de arte en Internet más interesantes es $<$ www.rhizome.org $>$, un colectivo de artistas, no jerárquico y sin fines de lucro que opera como "plataforma comunitaria para presentar un nuevo arte digital, mantener un diálogo crítico sobre este arte y proporcionar acceso mediante un archivo" (Gebhart, "Interview mit Mark Tribe”). Acaso Rhizome sea un buen ejemplo de una organización intermedia, entre el puro caos de la Internet y el control que buscan mantener las majors. Rhizome no repudia totalmente el arte institucionalizado; más bien procura reorganizarlo según principios no jerárquicos y no lucrativos. Podría decirse que es un buen modelo en el plano del arte para las protestas contra la globalización que, dicho sea de paso, también “encarnan” la metáfora rizomática y acaso por eso no han sido cooptadas. Desde luego, el arte se presta más para este tipo de práctica que el entretenimiento o los otros sectores de administración transnacional como la industria farmacéutica, que "siempre [han de] atenazarse en forma de monopolios y oligopolios” (Piscitelli, “Bertelsmann, MusicNet”).

Acaso las editoriales independientes de que habla Harari tendrían que adoptar este modelo, pero en ese caso también tendrían que enfrentarse con la escasez de usarios de Internet en América Latina. Evidentemente, el éxito del libro no va a producirse en sí sino en la producción de lectores/navegadores con capacidad crítica y estética. Por tanto, el futuro de la crítica dependerá de políticas culturales, sobre todo educacionales, pero también industriales. Por una parte, se necesita fomentar las destrezas de que habla Chartier, y por otra, es importante regular e inclusive combatir las condiciones que han impuesto las industrias culturales. Las políticas públicas del Brasil concernientes a la producción barata de medicamentos para el SIDA, contra el régimen de propiedad intelectual que la industria farmacéutica ha impuesto en los foros y tribunales internacionales, es un ejemplo de cómo es posible todavía proteger el bien público. Es decir, se pueden aprovechar los avances tecnológicos a la misma vez que se cultiva la interacción y la “creación de comunidad” a contrapelo. Pero, como explica César Bolaño, “para que eso tenga algún sentido, más allá de la pura ‘guerrilla simbólica’, y llegue a demostrar alguna eficacia, es preciso que los elementos concretos de la política sean activados en el interior del espacio que les es adecuado" (“La problemática” 39).

Por añadidura, las fundaciones y ONGs internacionales también tienen un papel importante tanto en el financiamiento educativo como en el activismo contra la transformación de bienes públicos en propiedad privada. Hasta la fecha, sus políticas culturales se han concentrado en el reconocimiento de las diferencias culturales, siguiendo la premisa de que ese reconocimiento abrirá el acceso a la participación ciudadana. Es decir, el trabajo de estas organizaciones se ha limitado a las vías de acceso a los escenarios de interlocución (Antonelli, “Nuevos escenarios”), pero no se han percatado de que esos escenarios ya han sido reestructurados bajo sus propias narices, y a menudo con su colaboración (v.gr., la alianza UNESCO-Disney). Incumbe, pues, a estas organizaciones intervenir en los foros donde se ha legitimado la abusiva apropiación de los bienes públicos por el nuevo régimen de acumulación centrado en el trabajo cultural. 
Álvarez, Sonia E. "Latin American Feminisms 'Go Global': Trends of the 1990s and Challenges for the New Millennium”. Cultures of Politics/Politics of Cultures: ReVisioning Latin American Social Movements. Sonia E. Álvarez, Evelina Dagnino y Arturo Escobar, eds. Boulder: Westview Press, 1998. 293-324.

Antonelli, Mirta. "Nuevos escenarios/nuevas interlocuciones. Para re-pensar las exclusiones. Elizabeth Jelin, Néstor García Canclini y Daniel Mato”. Ponencia presentada en Crosssroads in Cultural Studies, 3rd International Conference, Birmingham, UK. 21 a 25 de junio de 2000.

Arthurs, Alberta and Frank Hodsoll. "The Importance of the Arts Sector: How It Relates to the Public Purpose”. Journal of Arts Management, Law, and Society 28/2 (Summer 1998): 102-08.

Azpillaga, Patxi, Juan Carlos Miguel y Ramón Zallo. "Las industrias culturales en la economía informacional. Evolución de sus formas de trabajo y valorización”. Globalización y monopolios en la comunicación en América Latina. Hacia una economía política de la comunicación. Guillermo Mastrini y César Bolaño, eds. Buenos Aires: Editorial Biblos, 1999. 61-81.

Bakhtin, Mikhail. "The Problem of Speech Genres”. Speech Genres and Other Late Essays. Caryl Emerson y Michael Holquist, eds. Vern W. McGee, trad. Austin: University of Texas Press, 1986.

Beiguelman, Giselle. O livro depois do livro. 1999. http://www.desvirtual.com/giselle/ “Relatório_final.doc”2000.http://www.desvirtual.com/giselle/relatorio_final.doc

Bolaño, César. "La problemática de la convergencia informática-telecomunicacionesaudiovisual: un abordaje marxista”. Globalización y monopolios en la comunicación en América Latina. Hacia una economía política de la comunicación. Guillermo Mastrini y César Bolaño, eds. Buenos Aires: Editorial Biblos, 1999. 29-47.

Bonet, Lluís y Albert de Gregorio. “La industria cultural española en América Latina”. Las industrias culturales en la integración latinoamericana. Néstor García Canclini y Carlos Moneta, coords. Buenos Aires: Eudeba/SELA, 1999. 77-111.

“Boogie Woogie”. Latin Trade (July 1997). http://www.latintrade.com/archives/july97/ tradetalk.html

Castells, Manuel. The Rise of the Network Society. Oxford: Blackwell, 1996.

"La ciudad de la nueva economía”. La factoría 12 (julio-agosto 2000). http:// www.lafactoriaweb.com/articulos/castells12.htm

Chartrand, Harry Hillman. "Art \& the Public Purpose: The Economics of It All”. Journal of Arts Management, Law \& Society 28 (Summer 1998). http://www.art.net/lists/ announce/0033.html

Deleuze, Gilles y Félix Guattari. A Thousand Plateaus: Capitalism and Schizophrenia. Brian Massumi, trad. Minneapolis: University of Minnesota Press, 1987.

Dobrzynski, Judith H. "Blockbuster Shows Lure Record Crowds Into U.S. Museums". The New York Times (online) 3 de febrero de 2000. 
D’Onofrio, Ana. “Las nuevas tecnologías obligan a desarrollar una actitud crítica”, Entrevista a Roger Chartier: La Nación (online), 6 de mayo de 2001. http:// www.lanacion.com.ar/01/05/06/ dq_302961.asp

Dubner, Stephen J. “What Is Stephen King Trying to Prove?” The New York Times Sunday Magazine (13 de agosto de 2000).

Enríquez, Juan. “Technology and the Future of the Nation State”. Ponencia presentada en el Simposio sobre "Recentering the Periphery: Latin-American Intellectuals in the New Millennium”, The New School for Social Research. New York, 7 April 2000.

Fawcett, Michelle. “'It’s A Small Theme Park After All’: Partnerships Between UNESCO and The Walt Disney Company”. The Challenge of Cultural Policy. George Yúdice, ed. Minneapolis: University of Minnesota Press, (en prensa).

García Canclini, Néstor. “Author’s Preface to the English-Language Edition: The NorthSouth Dialogue on Cultural Studies”. Consumers and Citizens: Globalization and Multicultural Conflicts. Traducido por y con introducción de George Yúdice. Minneapolis: University of Minnesota Press, 2001. 3-13.

"Opciones de políticas culturales en el marco de la globalización”. Informe Mundial sobre la Cultura. Cultura, creatividad y mercados. Madrid: UNESCO-Acento-Fundación Santa María, 1999. http://www.innovarium.com/ Politicas/polcultglobalizacion.htm

Gebhart, Jens. "Interview mit Mark Tribe dem Gründer der Medien Kunst Plattform Rhizome.org in New York”. http://www.betacity.de/rhizome.htm

Getino, Octavio. "Las industrias culturales y el MERCOSUR". Contato: Revista Brasileira de Comunicação, Arte e Educação 2/6 (enero-mar. 2000): 53-61.

Greenhalgh, Liz. "From Arts Policy to Creative Economy”. Media International Australia, Incorporating Culture and Policy 87 (May 1998): 84-94.

Harari, Pablo. "La edición independiente en América Latina: un factor cultural en peligro”. Ponencia presentada en el Encuentro de Editores Independientes de América Latina. BID, OEI, FPH, UNESCO, OEA. Gijón, mayo, 2000.

Herscovici, Alain. “Globalización, sistema de redes y estructuración del espacio: un análisis económico”. Globalización y monopolios en la comunicación en América Latina. Hacia una economía política de la comunicación. Guillermo Mastrini y César Bolaño, eds. Buenos Aires: Editorial Biblos, 1999. 49-60.

Hopenhayn, Martín. “El reto de las identidades y la multiculturalidad”. Ponencia presentada en el Seminario "Nuevos retos y estrategias de las políticas culturales frente a la globalización”, Barcelona, Instituto d’Estudis Catalans, 22 a 25 de noviembre de 2000.

Lacarrieu, Mónica. “Construcción de imaginarios locales e identidades culturales en la mundialización”. Ponencia presentada en el Seminario "Nuevos retos y estrategias de las políticas culturales frente a la globalización”, Instituto d’Estudis Catalans, Barcelona, 22 a 25 de nov. de 2000.

“La Ley de Mecenazgo ya tiene media sanción del Congreso”. Clarín (19 de abril de 2001). http://www.clarin.com.ar/diario/2001-04-19/s-03901.htm

Mastrini, Guillermo y César Bolaño, eds. Globalización y monopolios en la comunicación en América Latina. Hacia una economía política de la comunicación. Buenos Aires: Editorial Biblos, 1999. 
Miller, Toby. "The Crime of Monsieru Lang: GATT, the Screen and the New International Division of Cultural Labour”. Film Policy: International, National and Regional Perspectives. Albert Moran, ed. Londres: Routledge, 1996. 72-84.

Mirapaul, Matthew. "Museums Find Many Eager to Help Them Sell Online”. The New York Times (online) 13 de junio de 2000.

Mosquera, Gerardo. “Arte y globalización en América Latina”. III Foro Latinoamericano. Museo Extremeño e Iberoamericano de Arte Contemporáneo. Badajoz, 21-23 de febrero de 2001.

Negus, Keith. Producing Pop. Culture and Conflict in the Popular Music Industry. Londres: Edward Arnold, 1992.

Olea, Raquel. "Brevísima relación de la literatura actual”. 1990-1994: la cultura chilena en transición. Santiago: Secretaría de Comunicación y Cultura, 1994.

Oliva, Glaucius. "Cerrando la brecha científica Latinoamerica debe adaptar el desarrollo tecnológico a sus propias necesidades”. www.cnnenespanol.com/time/, 28 de febrero de 2001; Inter-link Headline News 2221, 4 de marzo de 2001. Http://www.ilhn.com

Olodum. "Falando do Olodum.”. 1998. http://www.e-net.com.br/olodum/falando.html.

Ottman, Goetz. “Cultura é um Bom Negócio”. The Challenge of Cultural Policy. George Yúdice, ed. Minneapolis: University of Minnesota Press, (en prensa).

Palarea, Jordi. “La virtualización de las empresas”. La Vanguardia Digital. http://www. lavanguardia.es.

Pérez de Cuéllar, Pérez. Introduction. Our Creative Diversity: Report of the World Commission on Culture and Development. Paris: UNESCO, 1996. Online: http:// www.unesco.org/culture_and_development/ocd/foreword.html

Piscitelli, Alejandro. "Bertelsmann, MusicNet y el consumo musical después de Napster”. 5 de mayo de 2001. http://www.generacionnasdaq.com/\#

La Generación Nasdaq: Apogeo (¿y derrumbe?) De la economía digital. Buenos Aires: Ediciones Granica, 2001. http://www.generacionnasdaq.com/

Pompeu, Paulo de Tarso. "O Arte de Negócio”. Problemas Brasileiros (julho/agosto 1994): 13-18.

Rama, Ángel. Rubén Darío y el modernismo. Caracas: Alfadil Ediciones, 1985.

Redacción Punto-com. "Según El País, de España, Telefónica planea fundir a Terra y Telefónica Medios en una sola empresa, al estilo de AOL-Time Warner”. Punto-com 4 de mayo de 2001.http://www.punto-com.

Rapport d'activité 1998. París: Centre National du Livre, La documentation française, 1999.

Rehak, Judith. "Spain Is Betting Heavily On Latin American Ties”. The International Herald Tribune. 19 de marzo de 2001. http://www.iht.com

Richard, Nelly. “Globalizacion académica, estudios culturales y crítica latinoamericana”. Estudios Latinoamericanos sobre cultura y transformaciones sociales en tiempos de globalizacion. Daniel Mato, comp. Buenos Aires: CLACSO, 2001.

La insubordinación de los signos (cambio político, transformaciones culturales y poéticas de la crisis). Santiago: Editorial Cuarto Propio, 1994.

Rifkin, Jeremy. The Age of Access: The New Culture of Hypercapitalism, Where All of Life is a Paid-for Experience. Nueva York: Putnam, 2000. 
Rodríguez Lafuente, Fernando. Discurso, 14 Encuentro de Editores, Santander, 1998. Citado en Harari, “La edición independiente”, 14.

Sánchez, Matilde. “Los nuevos dueños de Babel”. Clarín (edición online) 6 de mayo de 2001.

Sarlo, Beatriz. "Modernidad y después: la cultura en situación de hegemonía massmediática”. Ponencia presentada en el Primer Encuentro de la Red Interamericana de Estudios Culturales, 4 de mayo de 1993; citado en Yúdice, Estudios culturales. "Se amplía brecha tecnológica entre países ricos y pobres, según la OIT”. Suple ILHN Inter-Link Headline News 2187. interlink@frontweb.net. 3 de feb. de 2001.

Tatti, Victoria. “Delich propone debatir el ingreso a la universidad”. Clarín (online) 5 de abril de 2001. http://www.clarin.com.ar/diario/2001-04-05/s-03801.htm

“Terra Lycos Signs Agreement With American Media for National Enquirer and Star Magazine Content”. Business Wire 26 de abril de 2001. http://nrstg1p.djnr.com/cgibin/DJInteractive?

Terranova, Tiziana. "Free Labor: Producing Culture for the Digital Economy”. Social Text 18, 2 (Summer 2000).

Wineland, John. "Rethinking the Philanthropic Ogre: The Privatization of Museums and Exhibitions in Mexico and Brazil”. Representing Latinamerican/Latino Art in the New Millennium: Curatorial Issues and Propositions. Mari Carmen Ramírez, ed. Austin: University of Texas Press, (en prensa).

Yúdice, George. "Estudios culturales y sociedad civil”. Revista de Crítica Literaria 8 (mayo de 1994): 43-53.

"Globalization and the New International Division of Cultural Labor”, Ponencia presentada en la Conferencia: "Globalization and Culture, New Perspectives for the New Millenium”, Institute for the Study of Economic Culture-Boston University \& New York University en Buenos Aires, 8 de diciembre de 2000.

"La industria de la música en el marco de la integración América Latina - Estados Unidos”. Integración económica e industrias culturales en América Latina. Néstor García Canclini y Carlos Moneta, eds. México: Grijalbo, 1999. 115-61.

"Producing the Cultural Economy: The Collaborative Art of inSITE". Beyond Identity: Globalization and Latin American Art. Luis Camnitzer y Mari Carmen Ramírez, eds. Minneapolis: University of Minnesota Press, (en prensa).

Zafra, J.M y R. Muñoz. “Telefónica impulsa el plan para integrar sus filiales de Internet y medios de comunicación”. El País (online), 4 de mayo de 2001. 